\title{
A resistively-heated dynamic diamond anvil cell (RHdDAC) for fast compression $x$-ray diffraction experiments at high temperatures
}

Cite as: Rev. Sci. Instrum. 91, 073906 (2020); https://doi.org/10.1063/5.0007557

Submitted: 13 March 2020 . Accepted: 12 June 2020 . Published Online: 14 July 2020

A. S. J. Méndez (D, H. Marquardt (D, R. J. Husband, I. Schwark, J. Mainberger, K. Glazyrin, A. Kurnosov, C. Otzen, N. Satta (D), J. Bednarcik (D), and H.-P. Liermann (D)

(1)

\begin{tabular}{|c|c|c|c|c|}
\hline $\begin{array}{c}\text { Nanopositioning } \\
\text { Systems }\end{array}$ & $\begin{array}{c}\text { Modular } \\
\text { Motion Control }\end{array}$ & $\begin{array}{c}\text { AFM and NSOM } \\
\text { Instruments }\end{array}$ \\
\hline MAD LITY LABS INC. \\
www.madcitylabs.com
\end{tabular}




\title{
A resistively-heated dynamic diamond anvil cell (RHdDAC) for fast compression $x$-ray diffraction experiments at high temperatures
}

Cite as: Rev. Sci. Instrum. 91, 073906 (2020); doi: 10.1063/5.0007557

Submitted: 13 March 2020 - Accepted: 12 June 2020 •

Published Online: 14 July 2020
A. S. J. Méndez,
H. Marquardt, ${ }^{3}$
R. J. Husband, 'I. Schwark,' J. Mainberger, ${ }^{1}$ K. Glazyrin,
A. Kurnosov,
C. Otzen, ${ }^{7}$ N. Satta, ${ }^{2}$
J. Bednarcik,
and H.-P. Liermann

\begin{abstract}
AFFILIATIONS
${ }^{1}$ Photon Sciences, Deutsches Elektronen-Synchrotron (DESY), 22607 Hamburg, Germany

2Bayerisches Geoinstitut BGI, University of Bayreuth, 95440 Bayreuth, Germany

${ }^{3}$ Department of Earth Sciences, University of Oxford, OX1 3AN Oxford, United Kingdom

${ }^{4}$ Department of Condensed Matter Physics, Institute of Physics, P.J. Šafárik University, 04154 Košice, Slovakia
\end{abstract}

a) Author to whom correspondence should be addressed: alba.mendez@desy.de

\begin{abstract}
A resistively-heated dynamic diamond anvil cell (RHdDAC) setup is presented. The setup enables the dynamic compression of samples at high temperatures by employing a piezoelectric actuator for pressure control and internal heaters for high temperature. The RHdDAC facilitates the precise control of compression rates and was tested in compression experiments at temperatures up to $1400 \mathrm{~K}$ and pressures of $\sim 130 \mathrm{GPa}$. The mechanical stability of metallic glass gaskets composed of a FeSiB alloy was examined under simultaneous high-pressure/high-temperature conditions. High-temperature dynamic compression experiments on $\mathrm{H}_{2} \mathrm{O}$ ice and $(\mathrm{Mg}, \mathrm{Fe}) \mathrm{O}$ ferropericlase were performed in combination with time-resolved $\mathrm{x}$-ray diffraction measurements to characterize crystal structures and compression behaviors. The employment of high brilliance synchrotron radiation combined with two fast GaAs LAMBDA detectors available at the Extreme Conditions Beamline (P02.2) at PETRA III (DESY) facilitates the collection of data with excellent pressure resolution. The pressure-temperature conditions achievable with the RHdDAC combined with its ability to cover a wide range of compression rates and perform tailored compression paths offers perspectives for a variety of future experiments under extreme conditions.
\end{abstract}

Published under license by AIP Publishing. https://doi.org/10.1063/5.0007557

\section{INTRODUCTION}

Diamond Anvil Cells (DACs) are broadly used in (geo-)physics, chemistry, and materials science to explore material properties under extreme conditions of pressure $(P)$. The development of membrane-driven DACs and DACs driven by piezoelectric actuators (PEAs) (dynamic DACs, dDACs) has led to an increasing interest in performing experiments under dynamic compression. ${ }^{1-1}$ In particular, the recent combination of the $\mathrm{dDAC}$ with timeresolved x-ray diffraction experiments at synchrotron sources to study the crystal structure evolution and compression behavior of samples is highly promising. It has been shown that compression rates of $>100 \mathrm{TPa} / \mathrm{s}$ can be achieved, ${ }^{15}$ demonstrating the potential of the $\mathrm{dDAC}$ to access compression (strain) rates that bridge the gap between traditional static DAC experiments and dynamic shock/ramp compression measurements. dDACs have been used to study compression-rate dependencies and kinetics of phase transitions, ${ }^{10,16}$ probe metastable phases, ${ }^{4,6}$ and simulate processes during impact events. ${ }^{14}$ Besides the ability to vary the compression rates, the $\mathrm{dDAC}$ also enables the application of customized compression paths. Recent work applied sinusoidal pressure-oscillations to a solid sample, on top of a base pressure, to measure its elastic response. ${ }^{1}$ While these works have proven the potential of the $\mathrm{dDAC}$, experiments have so far been limited to room temperature conditions due to the temperature sensitivity of the piezo actuator driver.

However, to address research questions related to the deep Earth and other planetary bodies, as well as in physics, chemistry, and materials sciences, achieving experimental conditions of 
simultaneous high-pressure $(P)$ and high-temperature $(T)$ is essential. High- $P / T$ experiments with DACs are more complicated because of the high- $T$ degradation of the DACs and the contamination of the sample. A specific example is the experimental challenge encountered in high- $T$ DAC experiments on $\mathrm{H}_{2} \mathrm{O}$ ice. At high temperatures, reactions between the $\mathrm{H}_{2} \mathrm{O}$ sample and different metals that are regularly used as gasket materials, pressure markers, or as laser absorbers in laser-heated DACs are likely to occur. ${ }^{18-20}$ Lin et al. performed in situ high-P/T Raman spectroscopy and synchrotron $\mathrm{x}$-ray diffraction experiments employing static DACs to examine the behavior of $\mathrm{H}_{2} \mathrm{O}$ ice VII in the vicinity of its melting curve. ${ }^{19}$ In these experiments, different gasket materials, including Re were tested. They observed the appearance of additional Raman peaks at $35 \mathrm{GPa}$ and $1040 \mathrm{~K}$ consistent with those of $\varepsilon-\mathrm{O}_{2}{ }^{21}$ that may have been formed as a product of $\mathrm{H}_{2} \mathrm{O}$ dissociation induced by a reaction with Re. Similar difficulties were encountered in experiments with lithium in DACs. Frost et al. performed hightemperature dynamic compression across the melting of lithium employing a diamond anvil cell coupled with a gas membrane. ${ }^{22}$ Lithium damage to the anvil culets had restricted the $P / T$-conditions achieved in previous experimental studies. Frost et al. extended the experimental conditions at which lithium had been studied and argued that fast compression permits the experiment to be conducted on a shorter timescale than that of lithium-induced diamond anvil failure. Thus, faster compression may facilitate the collection of high- $P / T$ x-ray diffraction data in the DAC in cases where the sample is unstable and reacts with the anvils or gasket material.

Here, we present a resistively-heated dynamic Diamond Anvil Cell (RHdDAC) developed at the Extreme Conditions Beamline (ECB, P02.2) at PETRA III (DESY). The RHdDAC is able to dynamically compress samples at temperatures up to at least $1400 \mathrm{~K}$. The simultaneous collection of $\mathrm{x}$-ray diffraction data with an excellent pressure resolution is possible by the employment of the GaAs LAMBDA detectors. ${ }^{23}$ We discuss the applications of the RHdDAC setup to the study of $\mathrm{H}_{2} \mathrm{O}$ ice and $(\mathrm{Mg}, \mathrm{Fe}) \mathrm{O}$ ferropericlase at high- $P / T$.

\section{THE HIGH-TEMPERATURE DYNAMIC DIAMOND ANVIL CELL}

The RHdDAC setup is based on a modified version of a symmetric piston cylinder type DAC suitable for housing a resistive heater. ${ }^{24}$ The DAC is equipped with diamond anvils (type Ia standard design $\mathrm{x}=3.25$ from Almax easyLab) glued to a tungsten carbide seat on the upstream side and a cubic boron nitride ( $c$-BN) seat on the downstream side [Fig. 1(a)]. The heating system in the RHdDAC employs rigid graphite heaters similar to those used previously. ${ }^{25}$ The graphite heaters employed in this study have been manufactured at DESY and consist of disks of $11 \mathrm{~mm}$ in diameter and $1.2 \mathrm{~mm}$ thick with a conical aperture of $104^{\circ}$ in the center that allows the heaters to be placed around the diamond-anvils [Fig. 1(b)]. In order to prevent heat transport to the cell and electrical insulation, the graphite heaters are isolated from the diamondanvil-supporting seats by ceramic rings that are glued to the seats with air set cement (OMEGABOND $\left.{ }^{\mathrm{TM}} 400\right)$. The ceramic rings measure $12 \mathrm{~mm}$ in diameter and $0.5 \mathrm{~mm}$ in height. In contrast to flexible graphite heaters that were used in previous setups ${ }^{26-28}$ the employment of rigid graphite heaters facilitates an easier and cleaner sample loading, in particular, when it comes to liquid samples because the gasket can be placed more stably on the diamonds. Type$\mathrm{R}$ thermocouples are mounted on the anvil pavilion close to the tip of the diamonds for temperature measurements (referred to as T1 on the downstream side and T2 on the upstream side). The Rh-Pt alloy has a melting temperature of $1873 \mathrm{~K}$, setting an upper limit for the maximum temperature measurement in the current RHdDAC experiments. The wires of the thermocouples are separately guided out of the heating area through two grooves engraved in the bottom faces of the heaters [Fig. 1(b)]. In order to electrically insulate the thermocouples, the wires are coated and fixed to the diamond-anvils with ceramic adhesive (Cotronics Resbond 989 from Polytec PT). The adhesive has a low thermal conductivity of $2.16 \mathrm{~W} /(\mathrm{m} \mathrm{K})$ and serves also as a thermal insulator. Two $4.7 \mathrm{~mm}$ thick and $68 \mathrm{~mm}$ long molybdenum rods with flat tips are inserted in the DAC through (a)

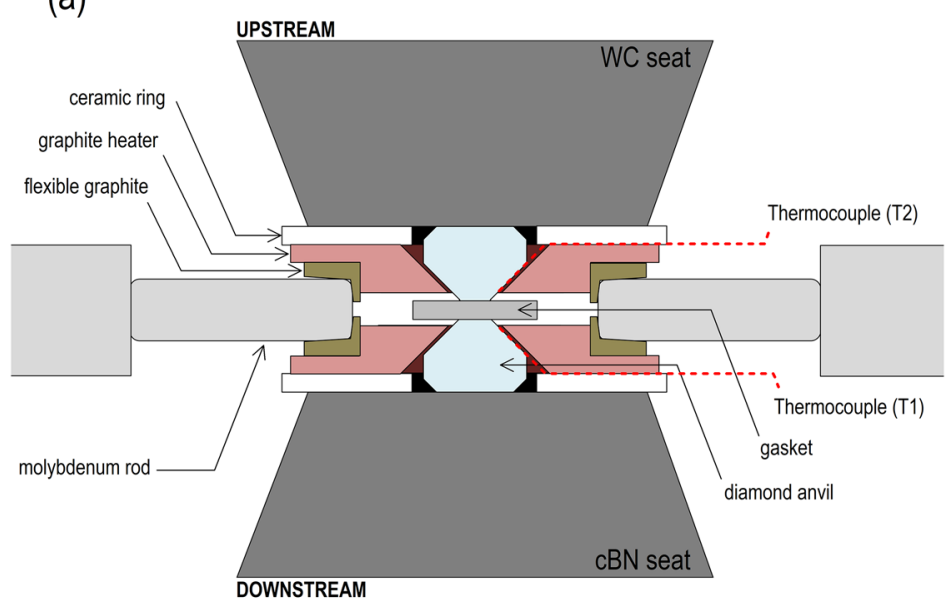

(b)

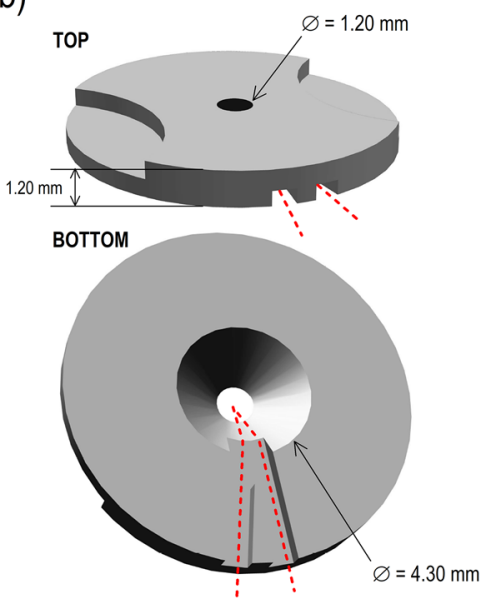

FIG. 1. (a) Cross section of the inside of the symmetric DAC showing the seated diamond anvils and the heating assembly. (b) 3D illustration of the rigid graphite heater, top and bottom views. The location of the thermocouples is indicated by dashed red lines. 
(a)

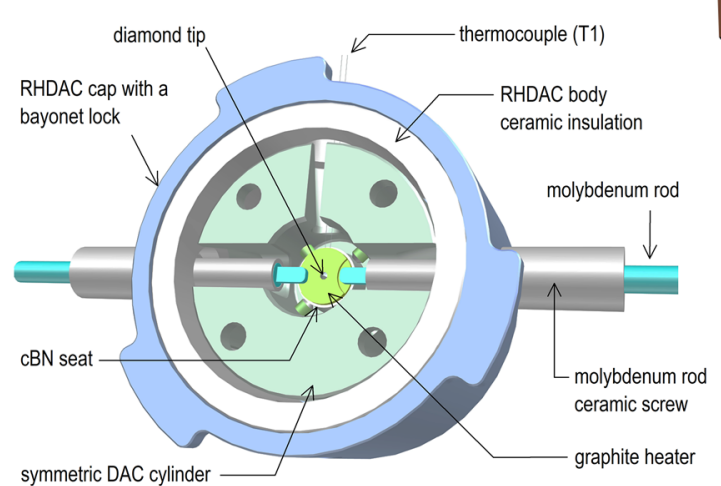

(b)

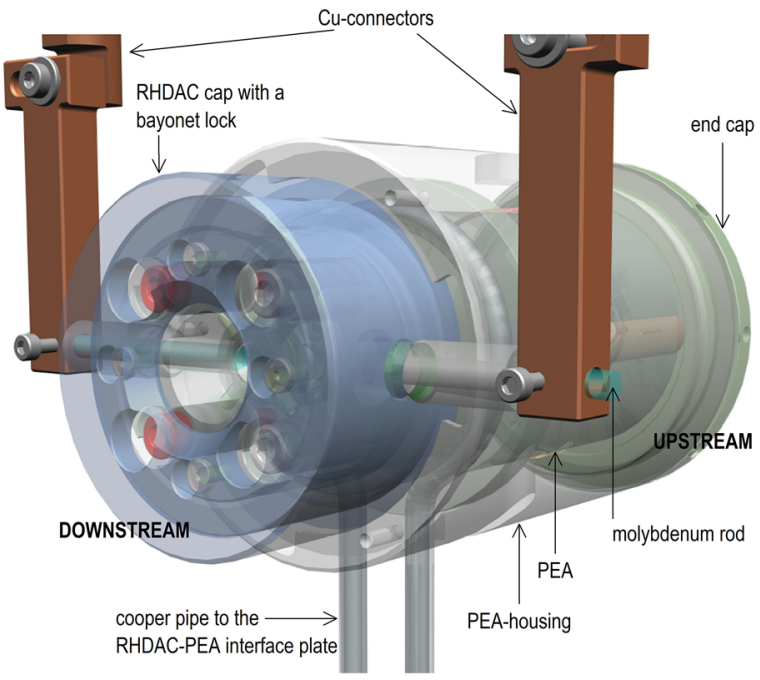

FIG. 2. Illustration of the connection of the DAC to the piezoelectric actuator. (a) Attachment of the symmetric DAC cylinder to the cap with a bayonet lock viewed from above. (b) Attachment of the RHDAC into the PEA-housing viewed from the downstream end.

two socket head screws made of aluminum oxide in order to keep the rods electrically insulated from the DAC body. The aluminum oxide screws have a major diameter of $10 \mathrm{~mm}$ and an inner diameter of $5 \mathrm{~mm}$ through which the rods pass through [Fig. 2(a)]. The flat tips of the rods are connected to the stiff graphite heater through sheets of flexible graphite to ensure a good electrical contact with the heaters on both sides. The resulting resistance of the heater is below $\sim 0.5 \Omega$. The molybdenum rods are connected to a DC power supply (8 V, 220 A, Agilent 6671A) through copper connectors [Fig. 2(b)].

The piezoelectric actuator (PEA) is coupled to the resistivelyheated DAC in a similar way, as described in Ref. 15. The PEA is enclosed in a hardened stainless steel case that is open at both ends. The symmetric DAC equipped with the heating system or resistiveheated DAC (hereafter referred to as RHDAC) is inserted into the downstream end by means of a cap with a bayonet lock [Fig. 2(a)]. The exterior of the cap is connected to a water-cooled aluminum holder [Fig. 3(a)]. The upstream end is closed through an end cap with fine threading that is tightened to engage the PEA with the RHDAC and pre-compress the sample if required. We choose a $60 \mathrm{~mm}$ long piezo stack actuator with a $9 \mathrm{~mm}$ through-hole (PIC255, a modified lead zirconate titanate from PI Ceramic $\mathrm{GmbH}$ ) that is compliant with the space limitations of the experimental setup at the Extreme Conditions Beamline ECB. ${ }^{29}$ The Curie temperature of the chosen piezoelectric material is $350^{\circ} \mathrm{C}$, according to the manufacturer specifications. To avoid the depolarization of the piezoelectric material, the recommended operating temperature is $<50 \%$ of the Curie temperature, i.e., $175^{\circ} \mathrm{C}$. In order to avoid the heating of the PEA above this temperature, it is thermally insulated from the RHDAC by a hardened stainless steel plate of $30 \mathrm{~mm}$ thickness that (a)

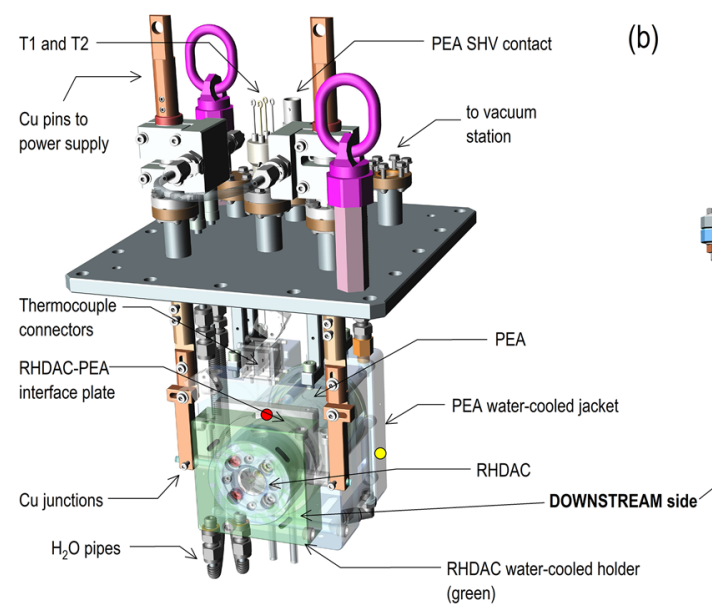

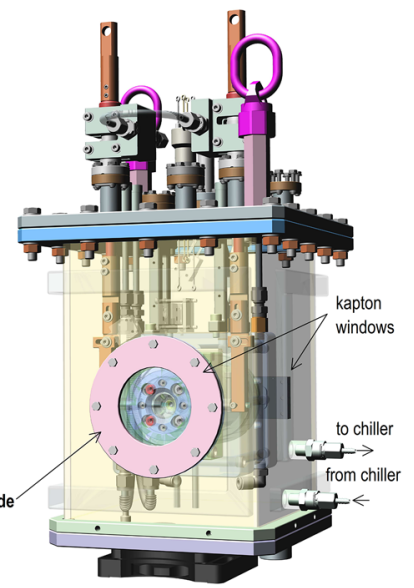

FIG. 3. (a) RHdDAC connected to the lid of the vacuum vessel. Red and yellow circles indicate approximate positions of T3 and T4 in the setup, respectively. (b) RHdDAC inserted into the vacuum vessel. 
is filled with ceramic insulation and encircled by a copper pipe at the interface between the RHDAC and the PEA [Fig. 2(b)]. The PEA is connected to an amplifier via a standard high voltage feedthrough (SHV-20 interface). When the PEA expands, it transmits the force to the piston of the RHDAC by pushing on the cooling plate. In addition, a box like water-cooled jacket is placed around the PEAhousing [Fig. 3(a)]. The water-cooled jacket consists of an outer aluminum case that is similar to the RHDAC cooling holder connected to a water chiller that is set to a cooling temperature of $5{ }^{\circ} \mathrm{C}$. In order to monitor the temperature in the PEA-housing, two Pt100 temperature sensors were placed on the PEA, close to the interface with the cooling plate (T3), and on the outer part of the cooling jacket (T4).

The RHdDAC assembly is permanently attached to the top lid of a vacuum vessel that was constructed to minimize the heat loss through air convection and avoid the oxidation of the setup as well as diamond graphitization. All the electrical connections (T1-T4, copper pins and PEA SHV-20 interface) and water pipes are guided through the lid of the vacuum chamber as shown in Fig. 3(a). The vacuum vessel consists of a water-cooled stainless steel chamber with a volume of $4.5 \mathrm{l}$, equipped with two Kapton windows that are located on the upstream and downstream sides [Fig. 3(b)] to let the incident beam and diffracted $\mathrm{x}$-rays pass. The total weight of the RHdDAC assembly together with the vacuum vessel is about $35 \mathrm{~kg}$.

\section{EXPERIMENTAL METHOD}

Monochromatic synchrotron high-energy radiation was used for time-resolved x-ray diffraction measurements at the Extreme Conditions Beamline P02.2 at PETRA III. ${ }^{29}$ The center of the sample chamber was aligned to a Compound Refractive Lenses (CRL) focused x-ray beam of $2(\mathrm{~h}) \times 8(\mathrm{v}) \mu \mathrm{m}^{2}$ (FWHM). In order to avoid the emergence of parasitic diffraction peaks due to the low- $Z$ character of the samples in comparison to the high- $Z$ Re gasket, inserts of metallic glass disks in the Re gaskets were employed. $50 \mu \mathrm{m}$ diameter holes were drilled in a $30 \mu \mathrm{m}$ thick foil of an amorphous alloy $\left(\mathrm{Fe}_{0.79} \mathrm{Si}_{0.06} \mathrm{~B}_{0.15}\right)$ using a Micro Electric Discharge Machine (EDM).
Disks were cut around the holes with an outer diameter of $96 \mu \mathrm{m}$ employing a laser micromachining tool so that the disks can be inserted in the Re gasket hole of $109 \mu \mathrm{m}$. Re and metallic glass are engaged by applying a small pressure with the diamond-anvils. Figure 4 shows a metallic glass gasket loaded with $\mathrm{H}_{2} \mathrm{O}$ and $\mathrm{Au}$ powder. An integrated diffraction pattern of the sample in comparison to a pattern of the sample loaded in a typical Re gasket is shown in Fig. 4(b). There is no significant contribution of the amorphous gasket to the background of the diffractogram. Before closing the cell loaded with the sample, the piston cylinder parts of the symmetric DAC are coated with Molykote lubricant paste in order to reduce friction between the cell parts at high temperatures.

Two GaAs 2.3 MPixel LAMBDA detectors were employed to perform the fast time-resolved collection of $\mathrm{x}$-ray diffraction images. ${ }^{23}$ Each of the detectors can collect x-ray diffraction images at a maximum repetition rate of $2 \mathrm{kHz}$. The detectors are used simultaneously and positioned horizontally on both sides of the incident $\mathrm{x}$-ray beam with each detector capturing about $20 \%$ of the Debye-Scherrer diffraction rings. The sample to detector distance (SDD) and tilting of the detectors are calibrated using a $\mathrm{Cr}_{2} \mathrm{O}_{3}$ standard from NIST (674b). Different exposure times can be employed on each detector to obtain datasets with different time resolutions during the same experiment.

A cartoon showing the control circuit for the RHdDAC setup at the ECB is illustrated in Fig. 5 and is similar to that described in Ref. 15. The DC power supply is connected to the graphite heaters and can be controlled remotely from the control room. Temperatures $\mathrm{T} 1$ and T2 are measured with a cold junction corrected multimeter (Keithley 3706A) and remotely monitored from the control room. T3 and T4 are read inside the experimental hutch with a data logger (RDXL 6SD from OMEGA) compatible with Pt100 temperature sensors that can display and record the temperature as a function of time. The vacuum vessel is connected to a vacuum pump that achieves pressures of $10^{-5}$ mbar at room temperature in the vessel and keeps the pressure below $10^{-3}$ mbar throughout the experiment at high temperatures. A water chiller (SL6 from Julabo) is used for cooling of the PEA-housing and the vacuum vessel. The PEA is (a)

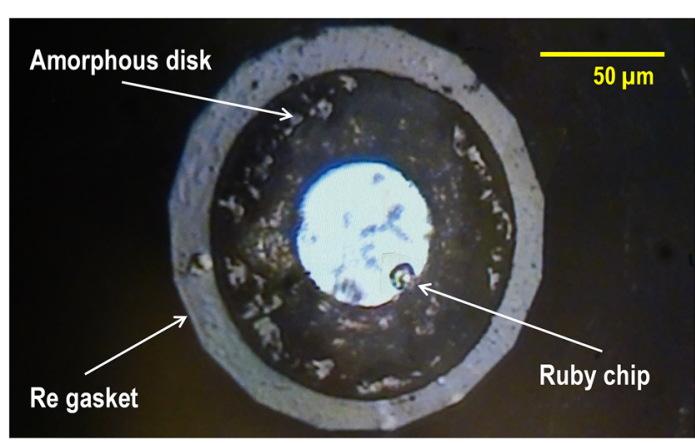

(b)

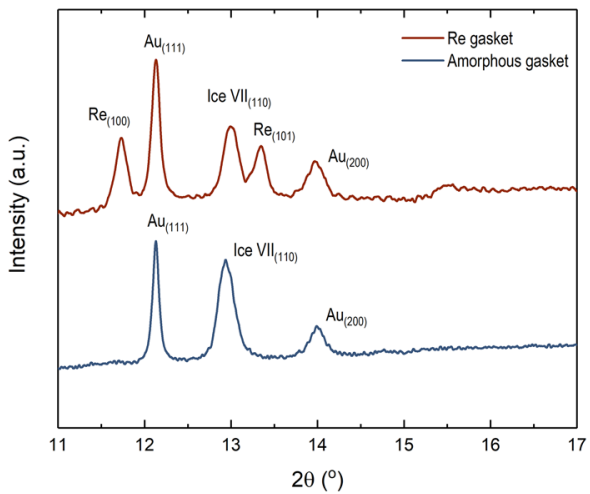

FIG. 4. (a) Picture of the sample chamber in a DAC viewed through the diamond culet. The loaded sample is $\mathrm{H}_{2} \mathrm{O}$ along with Au powder. (b) Raw integrated diffraction patterns from two samples containing $\mathrm{H}_{2} \mathrm{O}$ ice and Au powder loaded in a Re gasket (top) and an amorphous gasket (bottom). A detector artifact appears in the top pattern as a bump at $15.5^{\circ}$ 


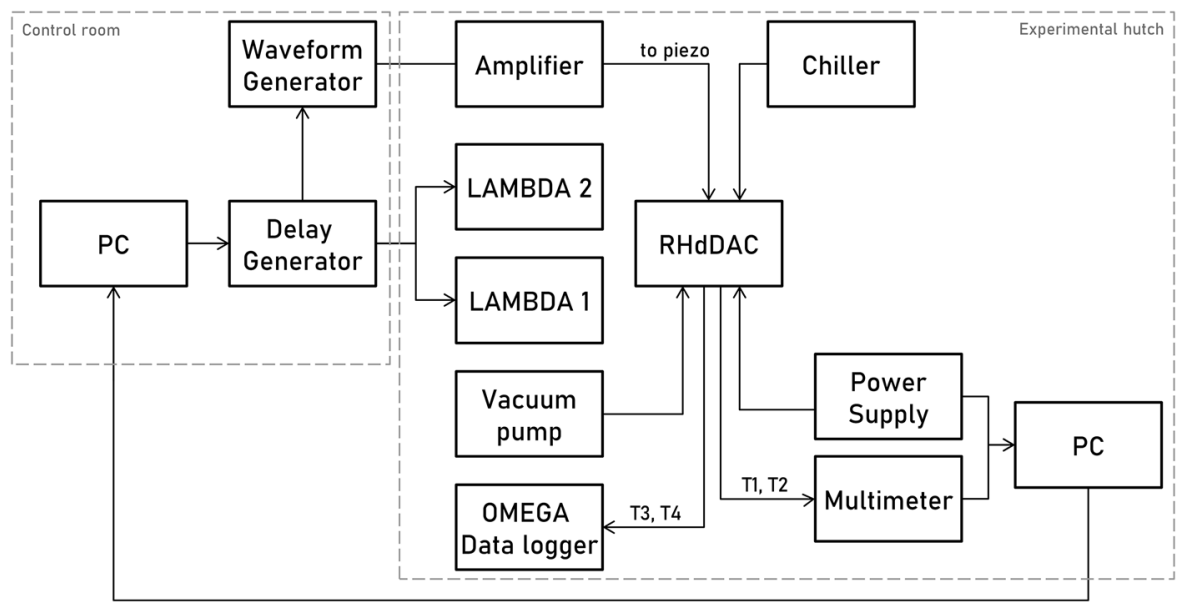

FIG. 5. Schematics of the experimental setup for RHdDAC experiments at the ECB. connected to an amplifier (1000 V, 7 A; Piezosystem Jena GmbH), which is controlled remotely from the control room through a waveform generator (Agilent 33522B). Arbitrary voltage-time waveforms can be created (see Sec. IV) by using the Agilent Benchlink waveform builder software from Keysight and sent to the PEA via the waveform generator.

\section{PERFORMANCE AND APPLICATION}

\section{A. Thermal expansion of $\mathrm{Au}$}

Even though thermocouples T1 and T2 are placed close to the tip of the diamonds, there may be a temperature difference between the thermocouple reading and the real temperature of the sample. We measured the thermal expansion of $\mathrm{Au}$ at room pressure to evaluate a possible temperature offset between the thermocouple readings and the sample. The temperature dependence of the lattice parameter of $\mathrm{Au}$ is well described in the literature and it has a melting temperature of $1337 \mathrm{~K},{ }^{30-32}$ making it a good temperature standard. Au powder (99.99\% pure from Sigma Aldrich) was loaded into a pre-indented Re gasket with $300 \mu \mathrm{m}$ culet diamonds, where the sample chamber was only partially filled to avoid pressure increase during heating. The RHdDAC setup was assembled following the described procedure (see Sec. III B) and the end cap was tightened in order to ensure a good contact between PEA and DAC. Two set screws between the piston and cylinder of the DAC prevented any pressure increase at high temperatures. The temperature was increased in $50 \mathrm{~K}$ steps up to a maximum temperature of $1200 \mathrm{~K}$ and the diffraction images were collected after each temperature increment. The unit cell volume of Au was derived from the (111), (200), (220), and (311) reflections and compared to the measurements from the literature (Fig. 6). ${ }^{32}$ Our results indicate a temperature difference smaller than $\pm 50 \mathrm{~K}$ [Fig. 6(b)], showing that there is an efficient heating of the sample in the RHdDAC.
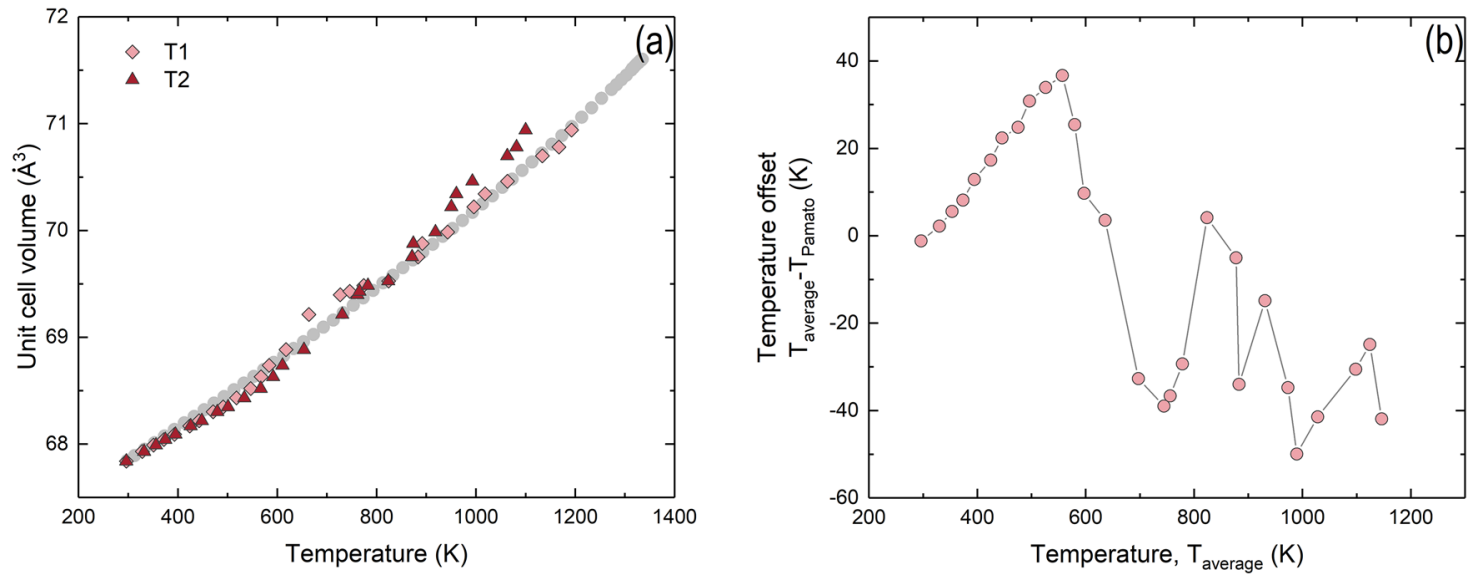

FIG. 6. (a) Experimentally determined unit cell volumes of Au as a function of the temperatures read from thermocouples T1 and T2 (diamonds and triangles) in comparison with the experimental data from Ref. 32 (solid circles). (b) Temperature offset with respect to Ref. 32 as a function of the average temperature of T1 and T2. 


\section{B. High pressure isotherms across the ice VII-ice $X$ stability fields}

$\mathrm{H}_{2} \mathrm{O}$ is a major constituent of planetary bodies in the outer Solar System and a wide range of exoplanets, where it condenses and crystallizes in different forms of ice at high pressures and temperatures. Establishing the boundaries between the different highpressure phases such as ice VII, ice X, and the superionic phase of ice at high temperatures, is of great importance in planetary science. We have explored the capabilities of the RHdDAC by compressing $\mathrm{H}_{2} \mathrm{O}$ ice VII at $450 \mathrm{~K}, 625 \mathrm{~K}, 865 \mathrm{~K}$, and $1043 \mathrm{~K}$ up to pressures of $110 \mathrm{GPa}$, i.e., across the stability fields of ice VII, ice $\mathrm{X}$, and possibly in the superionic phase (Fig. 7). High pressures were generated using beveled diamonds with $150 \mu \mathrm{m}$ diameter culets. Preindented Re gaskets were equipped with inserts of metallic glass as described above. Milli-Q $\mathrm{H}_{2} \mathrm{O}$ was loaded in the RHdDAC together with $\mathrm{Au}$ powder (99.99\% pure from Sigma Aldrich) as a pressure marker and a ruby chip to control the pressure in the sample during pre-compression up to $15 \mathrm{GPa}$. The temperature was increased in steps of $\sim 100 \mathrm{~K}$ until reaching the target temperature, collecting diffraction images at each step. The pressure significantly increased with the temperature in all the experiments possibly due to the overall thermal expansion of the RHdDAC parts. Once the target temperature was reached, the sample was continuously compressed using the PEA actuator while collecting time-resolved $\mathrm{x}$-ray diffraction data. Trapezoidal voltage-time waveforms were applied with compression rates ranging from $0.1 \mathrm{GPa} / \mathrm{s}$ to $0.3 \mathrm{GPa} / \mathrm{s}$ permitting comparably long exposure times of $500 \mathrm{~ms}$ while still achieving an excellent fine stepped pressure coverage with an average pressure spacing of about $0.2 \mathrm{GPa}$. Each $P-T$-path explored in our experiments (Fig. 7), including heating to the desired temperature before compressing with the PEA, was completed in about $40 \mathrm{~min}$. In RHdDAC experiments, experimental times are limited by the temperature of the PEA and/or sample stability. We noticed that for temperatures below $900 \mathrm{~K}$, the heat transfer to the PEA is efficiently counteracted by the cooling system, enabling experimental times of several hours. For experiments at temperatures above $900 \mathrm{~K}$, experimental times may be reduced significantly due to a rising temperature of the PEA. Additionally, the contact between heaters and molybdenum rods may change due to deformation during compression causing temperature fluctuations. However, these temperature fluctuations can be easily corrected by slightly re-adjusting the voltage.

According to the previously determined phase boundaries, the achieved $P-T$ conditions in our experiments are in the stability field of superionic ice. Data analysis is ongoing in order to confirm the observed $\mathrm{H}_{2} \mathrm{O}$ ice phases in our experiments and their compression behavior. No signs of the recrystallization of the metallic glass gasket at the sample-gasket edge were observed in our x-ray diffraction patterns. Furthermore, in contrast to widely used boron-epoxy amorphous gaskets, ${ }^{34,35}$ no reaction products between the sample and the gasket were detected in our experiments by x-ray diffraction and Raman spectroscopy measurements. The comparably short duration of the experiment may have prevented or at least significantly reduced the occurrence of chemical reactions, and/or $\mathrm{H}_{2} \mathrm{O}$ in the solid phases may not be as reactive at high temperatures as suggested previously.

\section{C. (Mg, Fe)O pressure oscillations under lower mantle conditions}

$(\mathrm{Mg}, \mathrm{Fe}) \mathrm{O}$ is the second most abundant mineral in Earth's lower mantle. ${ }^{38,39}$ The characterization of its elastic response is crucial to interpret seismic observations in terms of the mineralogy and dynamics of Earth's deep mantle. Using the RHdDAC, hightemperature pressure oscillation experiments were performed in
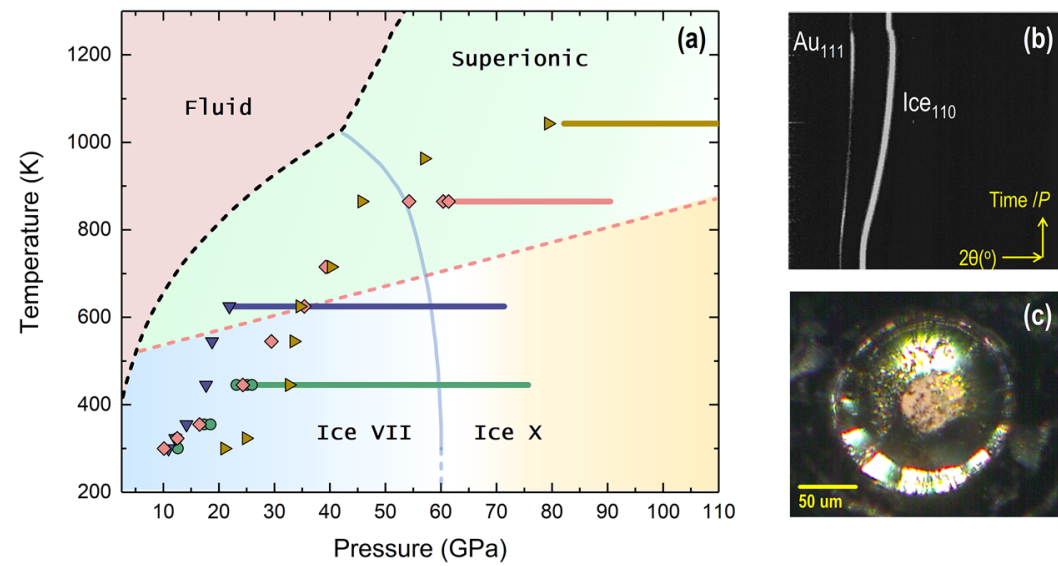

FIG. 7. (a) Experimental conditions reached during the experiments superimposed on the phase diagram of $\mathrm{H}_{2} \mathrm{O}$. Symbols (triangles, diamonds, and circles) represent experimental conditions where the diffraction data were collected while increasing the temperature and lines depict the pressure range covered during the dynamic compression at constant $T$. The pressure was determined from the (111) diffraction line of gold using the published equation of state parameters (Ref. 36). A solid blue line defines the ice VII-ice X boundary from Ref. 33. Dashed pink and black lines define the low temperature superionic phase boundary from Ref. 33 and the melting curve of ice from Ref. 37 , respectively. (b) A typical contour plot showing the time-evolution of diffraction patterns (peaks) collected at $625 \mathrm{~K}$; the $\mathrm{x}$-axis represents the diffraction angle (20) and the $\mathrm{y}$-axis is the time that is related to the pressure (Time/P). (c) Picture of the sample in the RHDAC after heating up to $1043 \mathrm{~K}$ in a metallic glass gasket setup. The sample remained centered during compression indicating that the employed gasket configuration was mechanically stable at high pressures and temperatures. 

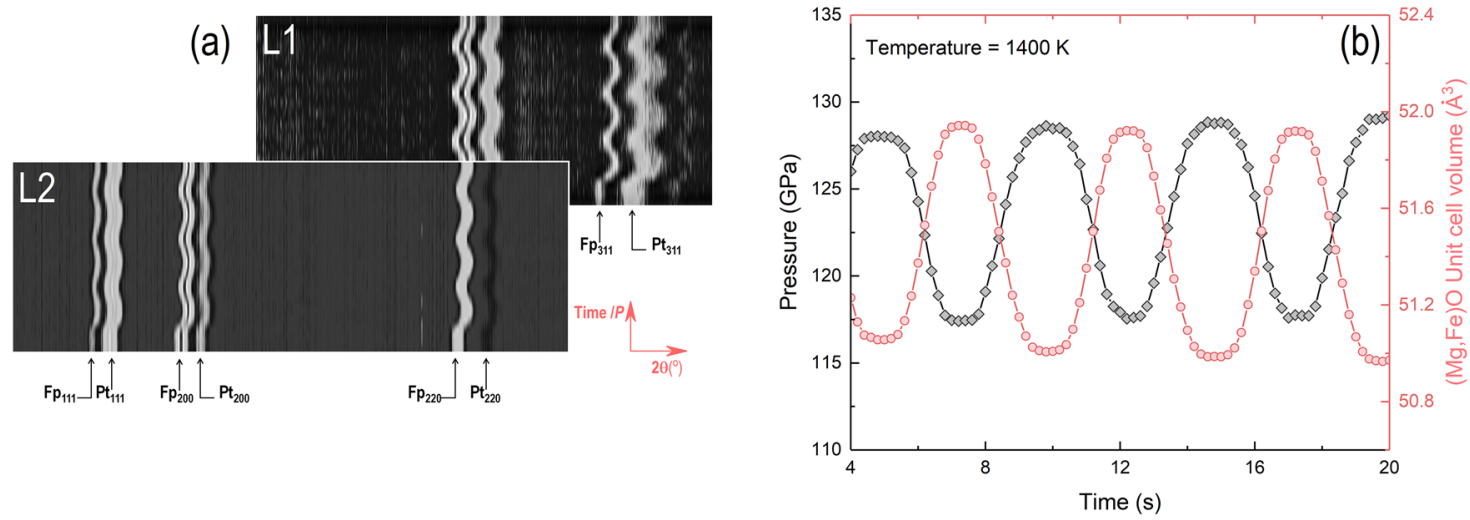

FIG. 8. (a) Contour plots from LAMBDA1 (L1) and LAMBDA2 (L2) showing the oscillating diffraction lines; the $x$-axis represents the diffraction angle (20) and the $y$-axis is time that is related to pressure (Time/P). (b) Platinum pressure and unit cell volume of ferropericlase as a function of time. The pressure was determined using the published equation of state parameters (Ref. 36). The response of both phases, platinum and ferropericlase, is in phase throughout the duration of the experiment.

order to study the elastic response of $\left(\mathrm{Mg}_{0.8} \mathrm{Fe}_{0.2}\right) \mathrm{O}$ ferropericlase and constrain the bulk modulus directly from the collected diffraction data following the approach outlined in Marquardt et al. ${ }^{17}$ Powder of $\left(\mathrm{Mg}_{0.8} \mathrm{Fe}_{0.2}\right) \mathrm{O}$ was synthesized from stoichiometric mixtures of the reagent grade $\mathrm{MgO}$ and $\mathrm{Fe}_{2} \mathrm{O}_{3}$ treated in a gas-mixing furnace at $1250^{\circ} \mathrm{C}$ at an oxygen fugacity of $2 \log$ units below the fayalitemagnetite-oxygen (FMQ) buffer. ${ }^{39}$ The sample was mixed with finegrained platinum powder used as a pressure marker (99.99\% pure from Sigma Aldrich). A metallic glass disk with a $50 \mu \mathrm{m}$ hole was inserted in a Re gasket pre-indented to a thickness of $30 \mu \mathrm{m}$ with $150 \mu \mathrm{m}$ culet diamonds. The $\left(\mathrm{Mg}_{0.8} \mathrm{Fe}_{0.2}\right) \mathrm{O}-\mathrm{Pt}$ mixture was loaded into the gasket hole and pre-compressed to $10 \mathrm{GPa}$ without a pressure-transmitting medium. The RHDAC with the loaded sample was attached to the PEA and the sample was further compressed by $1 \mathrm{GPa}-2 \mathrm{GPa}$ by tightening the end cap in order to ensure good contact between RHDAC and PEA. After achieving a good vacuum and stable cooling conditions, the sample was heated up to $1400 \mathrm{~K}$, taking diffraction images every $50 \mathrm{~K}$. At each $P$-T-step, four sinusoidal pressure oscillations with a frequency of $0.2 \mathrm{~Hz}$ were applied to the sample over a total time of $20 \mathrm{~s}$. Diffraction images were continuously collected by the LAMBDA detectors with single image exposure times of $200 \mathrm{~ms}$. In this experiment, the LAMBDA detectors were positioned off-center with respect to the incident $\mathrm{x}$-ray beam in order to enhance the $2 \theta$ range coverage, enabling the observation of a larger number of $\mathrm{x}$-ray diffraction lines [Fig. 8(a)]. For a preliminary analysis, the strongest peaks, the (200) line of ferropericlase, and the (111) line of platinum were chosen to derive the unit cell volume and the pressure, respectively [Fig. 8(b)]. The collected data demonstrate the potential of the RHdDAC to directly quantify the sample's bulk modulus at high-temperature and -pressure of the core-mantle-boundary, according to its thermodynamic definition $(K=-V * \partial P / \partial V)$.

\section{CONCLUSIONS}

In this paper, we present a resistively-heated piezo actuatordriven DAC (RHdDAC) for the compression of samples at temperatures up to $1400 \mathrm{~K}$ that was developed at the Extreme Conditions Beamline (ECB), PETRA III (DESY). We demonstrate the current capabilities of the novel setup for time-resolved $\mathrm{x}$-ray diffraction measurements. We used the RHdDAC to explore the phase diagram of $\mathrm{H}_{2} \mathrm{O}$ ice and were able to collect a large amount of x-ray diffraction data under a wide range of $P-T$ conditions while minimizing the duration of the experiments. The examination of the samples after the experiments suggested that fast compression may inhibit contamination reactions or induced diamond failure processes at high temperatures. We also collected x-ray diffraction data in the (presumably) low spin phase of ferropericlase by applying sinusoidal pressure oscillations with a frequency of $0.2 \mathrm{~Hz}$ at $1400 \mathrm{~K}$ in order to determine the sample's bulk modulus at high temperatures and lowermost mantle pressures. These experiments demonstrate the versatility of the RHdDAC setup. Our experiments further show the potential of metallic glass gasket inserts, which remained mechanically and chemically stable within the explored $P-T$ range, for x-ray diffraction measurements of low- $\mathrm{Z}$ materials. The expansion of the maximum temperature accessible with this setup will be possible by achieving a better understanding of the high- $T$ performance of the PEA and improving its thermal isolation.

\section{ACKNOWLEDGMENTS}

This research was supported through the DFG Research Unit FOR 2440 (Grant No. MA4534/5-1). We acknowledge DESY (Hamburg, Germany), a member of the Helmholtz Association HGF, for the provision of experimental facility PETRA III and Beamline P02.2. We acknowledge B. Winklers and the BMBF project (Reference No. 05K13RF1) that purchased the laser cutting machine for preparing the gaskets.N. Satta was funded by the International Research Training Group "Deep Earth Volatile Cycles” (GRK 2156/1) grant.

\section{DATA AVAILABILITY}

The data that support the findings of this study are available from the corresponding author upon reasonable request. 


\section{REFERENCES}

${ }^{1}$ W. J. Evans, C.-S. Yoo, G. W. Lee, H. Cynn, M. J. Lipp, and K. Visbeck, Rev. Sci. Instrum. 78, 073904 (2007).

${ }^{2}$ G. W. Lee, W. J. Evans, and C.-S. Yoo, Proc. Natl. Acad. Sci. U. S. A. 104, 9178 (2007).

${ }^{3}$ J.-Y. Chen and C.-S. Yoo, Proc. Natl. Acad. Sci. U. S. A. 108, 7685 (2011).

${ }^{4}$ J.-Y. Chen and C.-S. Yoo, J. Phys.: Conf. Ser. 377, 012109 (2012).

${ }^{5}$ D. Tomasino and C.-S. Yoo, Appl. Phys. Lett. 103, 061905 (2013).

${ }^{6}$ J.-Y. Chen, M. Kim, C.-S. Yoo, H.-P. Liermann, and W. J. Evans, J. Phys.: Conf. Ser. 500, 142006 (2014).

${ }^{7}$ Z. Konôpková, A. Rothkirch, A. K. Singh, S. Speziale, and H.-P. Liermann, Phys. Rev. B 91, 144101 (2015)

${ }^{8}$ S. V. Sinogeikin, J. S. Smith, E. Rod, C. Lin, C. Kenney-Benson, and G. Shen, Rev. Sci. Instrum. 86, 072209 (2015).

${ }^{9}$ J. S. Smith, S. V. Sinogeikin, C. Lin, E. Rod, L. Bai, and G. Shen, Rev. Sci. Instrum. 86, 072208 (2015).

${ }^{10}$ C. Lin, J. S. Smith, S. V. Sinogeikin, C. Park, Y. Kono, C. Kenney-Benson, E. Rod, and G. Shen, J. Appl. Phys. 119, 045902 (2016).

${ }^{11}$ E.-R. Carl, U. Mansfeld, H.-P. Liermann, A. Danilewsky, F. Langenhorst, L. Ehm, G. Trullenque, and T. Kenkmann, Meteorit. Planet. Sci. 52, 1465 (2017).

${ }^{12}$ E.-R. Carl, H.-P. Liermann, L. Ehm, A. Danilewsky, and T. Kenkmann, Meteorit. Planet. Sci. 53, 1687 (2018).

${ }^{13}$ A. Černok, K. Marquardt, R. Caracas, E. Bykova, G. Habler, H.-P. Liermann, M. Hanfland, M. Mezouar, E. Bobocioiu, and L. Dubrovinsky, Nat. Commun. 8, 15647 (2017).

${ }^{14}$ M. Sims, S. J. Jaret, E.-R. Carl, B. Rhymer, N. Schrodt, V. Mohrholz, J. Smith, Z. Konopkova, H.-P. Liermann, T. D. Glotch, and L. Ehm, Earth Planet. Sci. Lett. 507, $166(2019)$.

${ }^{15}$ Z. Jenei, H. P. Liermann, R. Husband, A. S. J. Méndez, D. Pennicard, H. Marquardt, E. F. O'Bannon, A. Pakhomova, Z. Konopkova, K. Glazyrin, M. Wendt, S. Wenz, E. E. McBride, W. Morgenroth, B. Winkler, A. Rothkirch, M. Hanfland, and W. J. Evans, Rev. Sci. Instrum. 90, 065114 (2019).

${ }^{16}$ G. W. Lee, W. J. Evans, and C.-S. Yoo, Phys. Rev. B 74, 134112 (2006).

${ }^{17}$ H. Marquardt, J. Buchen, A. S. J. Mendez, A. Kurnosov, M. Wendt, A. Rothkirch, D. Pennicard, and H. P. Liermann, Geophys. Res. Lett. 45, 6862, https://doi.org/10.1029/2018gl077982 (2018).

${ }^{18}$ B. Schwager, L. Chudinovskikh, A. Gavriliuk, and R. Boehler, J. Phys.: Condens. Matter 16, S1177 (2004).

${ }^{19}$ J.-F. Lin, Geophys. Res. Lett. 32, L11306, https://doi.org/10.1029/2005gl022861 (2005).
${ }^{20}$ A. Sano, E. Ohtani, T. Kondo, N. Hirao, T. Sakai, N. Sata, Y. Ohishi, and T. Kikegawa, Geophys. Res. Lett. 35, L03303, https://doi.org/10.1029/2007gl031718 (2008).

${ }^{21}$ M. Santoro, E. Gregoryanz, H. Mao, and R. J. Hemley, Phys. Rev. Lett. 93, 265701 (2004).

${ }^{22}$ M. Frost, J. B. Kim, E. E. McBride, J. R. Peterson, J. S. Smith, P. Sun, and S. H. Glenzer, Phys. Rev. Lett. 123, 065701 (2019).

${ }^{23}$ D. Pennicard, S. Smoljanin, F. Pithan, M. Sarajlic, A. Rothkirch, Y. Yu, H. P. Liermann, W. Morgenroth, B. Winkler, Z. Jenei, H. Stawitz, J. Becker, and H. Graafsma, J. Instrum. 13, C01026 (2018).

${ }^{24}$ B. Li, C. Ji, W. Yang, J. Wang, K. Yang, R. Xu, W. Liu, Z. Cai, J. Chen, and H. Mao, Proc. Natl, Acad. Sci. U. S. A. 115, 1713 (2018).

${ }^{25}$ Z. Du, L. Miyagi, G. Amulele, and K. K. M. Lee, Rev. Sci. Instrum. 84, 024502 (2013).

${ }^{26}$ H.-P. Liermann, S. Merkel, L. Miyagi, H.-R. Wenk, G. Shen, H. Cynn, and W. J. Evans, Rev. Sci. Instrum. 80, 104501 (2009).

${ }^{27}$ J. Immoor, H. Marquardt, L. Miyagi, F. Lin, S. Speziale, S. Merkel, J. Buchen, A. Kurnosov, and H.-P. Liermann, Earth Planet. Sci. Lett. 489, 251 (2018).

${ }^{28}$ J. Immoor, H. Marquardt, L. Miyagi, S. Speziale, S. Merkel, I. Schwark, A. Ehnes, and H.-P. Liermann, Rev. Sci. Instrum. 91, 045121 (2020).

${ }^{29}$ H.-P. Liermann, Z. Konôpková, W. Morgenroth, K. Glazyrin, J. Bednarčik, E. E. McBride, S. Petitgirard, J. T. Delitz, M. Wendt, Y. Bican, A. Ehnes, I. Schwark, A. Rothkirch, M. Tischer, J. Heuer, H. Schulte-Schrepping, T. Kracht, and H. Franz, J. Synchrotron Radiat. 22, 908 (2015).

${ }^{30}$ O. L. Anderson, D. G. Isaak, and S. Yamamoto, J. Appl. Phys. 65, 1534 (1989).

${ }^{31}$ R. O. Simmons and R. W. Balluffi, Phys. Rev. 125, 862 (1962).

${ }^{32}$ M. G. Pamato, I. G. Wood, D. P. Dobson, S. A. Hunt, and L. Vočadlo, J. Appl. Crystallogr. 51, 470 (2018).

${ }^{33}$ E. Sugimura, T. Komabayashi, K. Ohta, K. Hirose, Y. Ohishi, and L. S. Dubrovinsky, J. Chem. Phys. 137, 194505 (2012).

${ }^{34}$ J.-F. Lin, J. Shu, H. Mao, R. J. Hemley, and G. Shen, Rev. Sci. Instrum. 74, 4732 (2003).

${ }^{35}$ A. D. Rosa, M. Merkulova, G. Garbarino, V. Svitlyk, J. Jacobs, C. J. Sahle, O. Mathon, M. Munoz, and S. Merkel, High Pressure Res. 36, 564 (2016).

${ }^{36}$ Y. Fei, A. Ricolleau, M. Frank, K. Mibe, G. Shen, and V. Prakapenka, Proc. Natl. Acad. Sci. U. S. A. 104, 9182 (2007).

${ }^{37}$ A. F. Goncharov, C. Sanloup, N. Goldman, J. C. Crowhurst, S. Bastea, W. M. Howard, L. E. Fried, N. Guignot, M. Mezouar, and Y. Meng, J. Chem. Phys. 130, 124514 (2009).

${ }^{38} \mathrm{~T}$. Irifune and T. Tsuchiya, Treatise on Geophysics (Elsevier, 2015), pp. 33-60.

${ }^{39}$ H. Marquardt and L. Miyagi, Nat. Geosci. 8, 311 (2015). 